PONTIFÍCIA UNIVERSIDADE CATÓLICA DO RIO DE JANEIRO

A Importância do Planejamento Estratégico no Campo de Marketing: As Possibilidades de Desenvolvimento nas

Empresas

Luis Filipe M. Campelo

Trabalho de Conclusão de Curso

Centro de ciências sociais - CCS

DEPARTAMENTO dE AdMINISTRAÇÃO

Graduação em Administração de Empresas 
Luis Filipe M. Campelo

\section{A Importância do Planejamento Estratégico no Campo de Marketing: As Possibilidades de Desenvolvimento nas Empresas}

Trabalho de Conclusão de Curso

Trabalho de Conclusão de Curso, apresentado ao programa de graduação em Administração da PUC-Rio como requisito parcial para a obtenção do titulo de graduação em Administração.

Orientador(a) : Daniel Kamlot

Rio de Janeiro

Junho de 2021. 
A medida que o ritmo de mudança acelera, as empresas não podem mais confiar em suas antigas práticas de negócios manter a prosperidade. Kotler,

Philip (2003) 


\section{Agradecimentos}

Primeiramente gostaria de agradecer a Deus pelo dom da vida, saúde e colocar pessoas incríveis ao meu lado.

À minha Mãe, Elizabeth, por sempre ter me apoiado e ajudado durante toda a minha vida e trajetória acadêmica.

Ao meu pai, Luis Carlos, que sempre acreditou em mim e apoiou minhas decisões.

Ao meu orientador, Daniel Kamlot, pelos ensinamentos passados durante esse tempo para a elaboração do presente trabalho.

A todos os professores, que tornam o aprendizado e as salas de aulas em algo muito prazeroso, foi incrível ter a oportunidade de aprender com tantas pessoas incríveis e experientes.

E também à toda minha família, irmã, namorada e as pessoas mais próximas de mim, que não necessariamente presentes, participaram dessa trajetória. 


\section{Resumo}

Mattos Campelo, Luis Filipe. A Importância do Planejamento Estratégico no Campo de Marketing: As possibilidades de Desenvolvimento nas Empresas. Rio de Janeiro, 2021. 39 p. Trabalho de Conclusão de Curso Departamento de Administração. Pontifícia Universidade Católica do Rio de Janeiro.

Pensar o planejamento de marketing dentro de uma empresa é uma ação que requer o entendimento e domínio de técnicas que podem trazer resultados positivos para o desenvolvimento organizacional como um todo. É preciso pensar nesse caso que a forma como uma empresa é constituída tem total relação e segmentação com as ações que podem ser executadas dentro desse cenário compreendendo aí que o planejamento deve ser coerente com as necessidades de crescimento e o cumprimento de metas estipuladas dentro de um modelo de ação. Nesse contexto, o presente trabalho tem como foco discutir, a importância da elaboração de um planejamento de marketing para empresas que precisam elaborar estratégias especificas para alcançar seus clientes e manter a sua fidelização. Trata-se de um trabalho que surge da percepção analítica para a consideração desse tipo de ação para empresas que atuam como clubes de serviços, reconhecendo aí a necessidade de se validar ações que representem uma forma de agir diferenciada e eficaz, também coerente com o modelo de ação exigido dentro do cenário que a cada dia se torna mais digital.

Palavras-Chave: Elaboração de estratégias. Modelo de Ação. Planejamento de Marketing. 


\section{Abstract}

Mattos Campelo, Luis Filipe. The Importance of Strategic Planning in the Marketing Field: The Possibilities for Development in Companies. Rio de Janeiro, 2021. 39 p. Trabalho de Conclusão de Curso - Departamento de Administração. Pontifícia Universidade Católica do Rio de Janeiro.

Thinking about marketing planning within a company is an action that requires understanding and mastering techniques that can bring positive results for organizational development as a whole. It is necessary to think in this case that the way a company is constituted is fully related and segmented with the actions that can be performed within this scenario, understanding that the planning must be coherent with the needs for growth and the fulfillment of stipulated goals within a Action model. In this context, this work focuses on discussing the importance of developing a marketing plan for companies that need to develop specific strategies to reach their customers and maintain their loyalty. This work arises from the analytical perception to consider this type of action for companies that act as service clubs, recognizing the need to validate actions that represent a differentiated and effective way of acting, also consistent with the model. of action required within the scenario that is becoming more digital every day.

Keywords: Strategies elaboration. Action Model. Marketing Planning. 


\section{Sumário}

1 Introdução 1

2 Contexto e realidade investigada 3

3 Diagnóstico da situação problema e oportunidade 9

3.1. Plano de ações para viabilidade das medidas de marketing 10

4 Análise da situação e proposta de solução 17

$\begin{array}{ll}\text { 4.1. Proposições } & 17\end{array}$

4.1.1. Estratégia de ação 19

5 Conclusões e contribuições do estudo Erro! Indicador não definido.

5.1. Apontamentos Finais Erro! Indicador não definido.

6 Referências 


\section{Lista de figuras}

Figura 1: Processo de organização

Figura 2: Dimensões Operacionais do Planejamento Estratégico 


\section{Introdução}

A prestação de um serviço ou o fornecimento de bens, para a satisfação das necessidades das pessoas, são iniciativas que nascem da visão e decisão de indivíduos que colocam suas forças e dedicação nesse objetivo.

Para Sousa et.al (2018), o Planejamento Estratégico tem servido como uma competência utilizada cada vez mais pelos gestores no mundo empresarial na busca de resultados satisfatórios e desejados.

Fatores financeiros deixaram de exclusivamente decisivos para o sucesso de um empreendimento, e, nesse sentido, Gohr e Santos (2015) afirmam que, na maioria das vezes, a ausência de um planejamento estratégico antes da abertura do negócio e durante a sua operação é o principal fator que leva ao fracasso das Micro e Pequenas Empresas (MPEs), sendo, portanto, fundamental sua formulação para garantir a permanência ativa e o desenvolvimento do negócio. Ainda de acordo com Gohr e Santos (2010), com o planejamento estratégico, torna-se possível à empresa ter uma visão mais ampla de seus contextos de atuação, o que possibilita identificar os potenciais riscos e oportunidades associados ao negócio.

Relevantes instrumentos do planejamento estratégico são as estratégias corporativas, que conduzem os processos/negócio aos objetivos gerais, metas, políticas entre outros, determinados pela organização no seu exercício a fim de garantir uma situação futura desejada. Dessa forma, o planejamento caracterizase como um instrumento com o qual as organizações colocam em prática suas estratégias com foco na eficiência e eficácia de suas ações e atividades. (SILVA; LEON 2015).

Porter (1986) afirma que a estratégia competitiva é o método utilizado pela empresa para conseguir um posicionamento vantajoso no mercado e também uma rentabilidade em longo prazo. Afirma também que é necessário, para o desenvolvimento de uma estratégia, pesquisar, de forma analítica, suas forças competitivas.

A falta de planejamento é relacionada como um fator determinante para a mortalidade das empresas (SILVA; LEON, 2015), especialmente ao que tange à constância do planejamento. Nesse sentido, é pertinente citar que, sem a realização de um planejamento direcionado à resolução dos problemas da empresa, o que se tem é a possibilidade de engate de um modelo ineficaz e com 
ações soltas, voltadas ao "achismo", empíricas e desconexas com a realidade enfrentada pelo negócio.

Tendo como pano de fundo essa discussão inicial apresentada, destacase que o presente trabalho tem como objetivo geral discutir a importância do planejamento de marketing para empresas expondo de modo conjunto de ações pertinentes a ser aplicado, considerando para isso a viabilidade de aprofundamento teórico no que se refere à usabilidade e aplicabilidade de ferramentas que contribuem de forma especifica para a consideração de medidas que podem influir positivamente na usabilidade de técnicas diferenciadas dentro da abordagem de marketing. (VARGAS, 2015)

Seus objetivos específicos, por sua vez, se organizam na contemplação inicial sobre o que é e qual a importância da abordagem estratégica dentro da elaboração de um planejamento de marketing, para seguidamente discutir os conceitos referentes às ferramentas importantes como 0 CANVAS, Brainstorming e SWOT e por fim, explana os passos do planejamento estratégico dentro de uma organização.

Para a construção dessa abordagem foi adotado o método de análise bibliográfica das fontes escolhidas para a fundamentação do texto. Com a usabilidade desse método, se elabora o modelo de revisão de literatura que faz uso de uma pesquisa exploratória que avalia variadas fontes de referenciação teórica, que torna a abordagem aqui apresentada mais coesa e diversa no que se refere à compreensão dos temas propostos. 


\section{Contexto e realidade investigada}

As relações comerciais fazem parte da vida dos seres humanos em diversas localidades, utiliza-se desse recurso para que se troquem produtos, serviços, informações, já que para o homem viver em comunidade é necessário assegurar o alimento de sua família, moradia, roupas para se aquecer ou qualquer recurso que se precise. Nessa relação de trocas entre pessoas ou grupos, se criam vários mecanismos para que se possam estabelecer as maneiras de se comercializar. (TAVARES, 2013)

Com a evolução da sociedade é pertinente que se tenha também uma evolução nas relações comerciais, neste caso, pode-se dizer que as mudanças irão afetar mais especificamente a divulgação de produtos e serviços aos consumidores, pois essa nova clientela traz consigo percepções do que se quer consumir de uma maneira diferenciada da existente no mercado consumidor. Essa nova visão requer uma proximidade por aquele que oferece o produto, além de características que sejam identificadas pelo consumidor como únicas e personalizadas. (MOREIRA, 2015)

De acordo com Andrade (2012) o principal objetivo do marketing é gerar lucro para a organização, atender as necessidades dos consumidores e constituir uma cultura na qual toda a sociedade se sinta beneficiada com os produtos. Para o autor, as principais ações do marketing são inovar, comunicar, valorizar e interagir.

$\mathrm{Na}$ visão de Kotler e Armstrong (2015) o marketing consiste em administrar os relacionamentos com os consumidores, atraindo clientes com algo inovador com a oferta de produtos que proporcionam satisfação.

O ciclo de vida de um produto pode ter uma influência direta na sobrevivência da companhia. O ciclo de vida de um produto consiste de quatro estágios: introdução, crescimento, maturidade e declínio. O conceito de vida do produto aplica-se a uma categoria genérica de produtos não a marcas específicas (ETZEL E WALKER, 2016, p. 230).

Evidencia-se que os objetos e serviços comercializados possuem períodos de grande e pequena oscilação no mercado, de modo que este é um aspecto que compõe a trajetória de todo e qualquer bem de consumo.

Convém enfatizar a importância de aproveitar as oportunidades em que determinado produto está em evidência, sendo esse um momento propício para abordar os clientes, explorar a curiosidade e a disposição desses ao consumo e 
finalmente conquistar o melhor posicionamento do produto perante o mercadoalvo (Las Casa, 2016).

Diante do posicionamento da marca, destacam-se as características dos produtos por ela ofertados, tanto no que tange ao ciclo de vida em que os produtos se encontram, quanto na qualidade a eles atreladas, sendo fundamental que o produto possua uma identidade, ou seja, uma denominação própria que o faça ser lembrado de maneira singular.

Para Gomes (2013, p. 182) "marca é um nome, termo, sinal, símbolo ou desenho, ou uma combinação dos mesmos, que pretende identificar os bens e serviços de um vendedor ou grupo de vendedores e diferenciá-los".

No âmbito da qualidade, de modo que a existência de padrões elevados de controle capazes de garantir o cumprimento das especificações que uma empresa se propõe a atender no desenvolvimento de um produto, ou na prestação de um serviço, é fundamental para garantir a credibilidade, bem como a fidelização dos clientes.

Segundo Gomes (2013, p. 183) "tudo o que se diz do produto é o ideal e, por sua vez, tudo o que foi idealizado se demonstra através dele". Desta forma, torna-se fundamental que as organizações zelem pela qualidade de seus produtos e serviços, uma vez que qualquer falha no atendimento às especificações previamente acordadas pode ferir a imagem e a credibilidade da empresa.

O preço é o valor monetário aplicado a um produto, ou serviço, que visa ser comercializado. A partir disso, Churchill e Peter (2015, p. 314) concebem o preço como "a quantidade de dinheiro, bens ou serviços que deve ser dada para se adquirir a propriedade ou uso de um produto".

Por esse modo, um aspecto fundamental a ser considerado é a adequação do valor percebido pelo cliente e o valor monetário, de modo que deve existir um equilíbrio entre essas duas variáveis.

Para os autores acima os profissionais de marketing definem o preço de um produto ou serviço, devem ser considerados todos os fatores psicológicos que, de uma forma ou de outra, são importantes para os consumidores.

Desta forma, convém que a empresa se utilize de métodos e técnicas capazes de elevar o valor percebido dos produtos, de maneira que os esforços sejam recompensados com a ampliação das vendas e com a possibilidade de aumentar o preço dos produtos em questão. (KANDYBIN; GROVER, 2019)

Quanto à localização do ponto-de-venda, há importância da visibilidade oferecida em cada situação, sendo as esquinas os locais mais valorizados nesse 
aspecto, seguidas dos trechos de rua voltados para praça, largo ou final e começo de rua (UGAYA, 2019).

Assevera-se que na visão apresentada por Etzel e Walker (2016, p. 348) "o papel da distribuição dentro de um Mix de Marketing é levar o produto até seu mercado-alvo. Nesse processo, a atividade mais importante é acertar sua venda e a transferência da propriedade, do produtor ao consumidor final".

Para McCarthy e Perreault (2017, p. 230) a promoção é tida como "a comunicação da informação entre vendedor e comprador potencial ou outros do canal para influenciar atitudes e comportamento".

Destaca-se que a função básica da promoção está em expor aos clientes que o produto desejado por eles está à disposição, apresentando um preço adequado aos seus benefícios, e que o referido produto está acessível em um determinado ponto-de-venda.

Segundo a visão defendida por Kandybin e Grover (2019, p. 44) “o marketing e a publicidade podem sempre se apresentar e transformar um conceito 'mais ou menos' em sucesso de vendas".

Para os mesmos autores, tal assertiva denota a relevância da adoção de medidas coerentes no que concerne à aplicação das estratégias promocionais, sendo essa uma ferramenta essencial no posicionamento de uma marca ou produto no âmbito mercadológico.

Segundo De Sordi (2020), as empresas que estão sempre pensando no futuro têm maior possibilidade de resistir a uma crise, seja em um momento de crise financeira, ou mesmo em um contexto como o da pandemia da Covid-19, em que todo o mundo vive momentos de restrição, mas possível que as empresas continuem a crescer, se observarem as oportunidades que podem surgir à sua volta.

Nesse sentido, se observa que a postura estratégica de uma empresa tem sido de constante observação e análise dos cenários que surgem, com o foco de fazer com que sejam cumpridos os requisitos mínimos de qualidade e de interação com seus clientes. Para tanto, se tem no entendimento de Brocka (2019) que a postura estratégica de uma empresa é estipulada de acordo com a sua necessidade e metodologia de crescimento.

Por esse motivo, é importante se validar que as posturas adotadas dentro do contexto organizacional, sejam pertinentes ao cenário em que a empresa atua. Logo, não há um padrão estratégico pronto para ser aplicado a uma organização, trata-se de uma ação individual que tem de estar articulada com todas as necessidades da empresa. 
A escolha da estratégia deve ser levada em consideração pela organização, é necessário ter o seu conhecimento fundamental como descrito por Mintzberg (2010), e Oliveira (2018, p.15) enfatiza que "infelizmente, grande número de empresas não tem ou não sabe quais são suas estratégias", e aponta como a principal razão por que muitas empresas estabelecidas fracassam em seus objetivos e esforços empenhados, seja em um programa de aquisição de outra empresa, diversificação de produtos ou expansão de mercado.

As estratégias devem ser estabelecidas de acordo com a necessidade da empresa, a determinação dos objetivos deve guiar sua escolha em detrimento aos da organização, e segundo Mintzberg e Waters (1985), requer sensibilização, em um grau elevado que caracterize a eficácia dos gestores e a eficácia das organizações.

Elaborar uma estratégia competitiva é o mesmo que elaborar um método amplo para a maneira em que a empresa irá competir, quais seriam as suas metas e quais caminhos seguir para atingir essas metas (PORTER, 1986).

Para Oliveira (2018) a formulação da estratégia é um dos aspectos mais importantes que você enfrenta no processo de elaboração do planejamento estratégico, pois é complexa e depende de inúmeros fatores e condições que se alternam e se modificam incessantemente.

Segundo Ansoff (1990), a estratégia diz respeito basicamente à utilização dos diversos recursos empresariais, sejam eles: humanos, técnicos ou financeiros, que estão à disposição do empresário.

Para Fernandes e Berton (2005), não basta um propósito ou uma boa disposição para concretizar uma situação futura desejada. É necessário elaborar planos, estabelecer políticas, definir caminhos a serem percorridos e efetivar ações para viabilizar esses desejos.

Muitas empresas de sucesso não estão conscientes das estratégias, assim seu resultado é puramente intuitivo. É bem possível para uma empresa alcançar um sucesso inicial, sem real conscientização de suas causas; entretanto, é muito mais difícil continuar bem, ramificando-se em novos empreendimentos e negócios, sem a apreciação exata do significado de suas estratégias básicas.

O primeiro estágio no desenvolvimento de uma estratégia útil, portanto, é identificar, em um nível fundamental, as causas dos problemas que a empresa precisa abordar (CHRISTENSEN, 1997).

A escolha da estratégia deve ser levada em consideração pela organização, é necessário ter o seu conhecimento fundamental como descrito 
por Mintzberg (2010), e Oliveira (2018, p 21) enfatiza que "infelizmente, grande número de empresas não têm ou não sabe quais são suas estratégias", e aponta como a principal razão por que muitas empresas estabelecidas fracassam em seus objetivos e esforços empenhados, seja em um programa de aquisição de outra empresa, diversificação de produtos ou expansão de mercado.

Dessa forma, o autor enfatiza que é de suma importância entender o seu negócio, para que seja possível escolher o tipo de estratégia mais adequado.

Nesse contexto, há que se citar que são muitas as organizações que se encontram alheias à importância da adoção de estratégias, e portanto, suas primeiras ações dentro de um processo administrativo são puramente intuitivas. Mesmo assim, é preciso se reiterar que há, sim, a possibilidade de haver êxito dentro desse processo administrativo, contudo, as possibilidades de erro são superiores à probabilidade de acerto, o que, por si só, já justifica a importância de se ter uma ação mais votada ao reconhecimento de que um planejamento é essencial dentro de uma organização. (CAMILO, 2013).

O primeiro estágio no desenvolvimento de uma estratégia útil, portanto, é identificar, em um nível fundamental, as causas raízes dos problemas que a empresa precisa abordar (CHRISTENSEN, 1997).

Oliveira (2018) cita o Fator Estratégico como informação de grande valor ao desenvolvimento da estratégia, isso porque ele também se caracteriza como um fator de limitação do sistema, ou seja, são fatos e situações que podem interromper o adequado funcionamento de um processo, como por exemplo uma máquina qualquer que não esteja funcionando por falta de um parafuso; nesta situação, o parafuso é classificado como o fator estratégico, e o autor enfatiza que esses fatores precisam ser identificados e aperfeiçoados pela empresa para que seja bem sucedida.

As estratégias alternativas são elementos desenvolvidos no percurso do processo de elaboração da estratégia e que abordam o processo criativo na formulação de uma lista de ações estratégicas relacionadas aos problemas elencados na organização, visando atender aos objetivos, desafios e metas previamente definidos. Para Oliveira (2018), sua finalidade básica é o estabelecimento de alternativas de ação que englobem as possíveis configurações da empresa perante o binômio produtos e serviços versus segmentos de mercado.

Sua elaboração é uma parte importante na montagem da estratégia, pois ela indicará os caminhos pelos quais as ações serão conduzidas e o quão diversificado foram os caminhos percorridos ao encontro das possíveis soluções. 
E nesse momento o conhecimento e intimidade nos processos e problemas organizacionais, juntamente com a precisão e coerência na formulação das propostas, somam para a exploração e criação de ações assertivas. Contudo, nem todas são necessariamente aproveitadas - ao final devem ser eleitas, pelo executivo, as mais adequadas aos interesses empresariais. Oliveira (2018) destaca que para que tais configurações possam ser consideradas adequadas pelos executivos, é necessário que cada uma delas seja dimensionada de modo que se tornem:

- Competitivas;

- Correlacionadas entre si; e

- Possíveis de serem operacionalizadas com recursos que estão à disposição da empresa no momento considerado.

Os itens listados indicam a necessidade da criação de estratégias alternativas apropriadas ao contexto explorado, é necessário que haja um potencial de criação de alternativas criativas, efetivas aos objetivos, claras, e que tenham a capacidade de realização para que os propósitos sejam alcançados.

Para Mintzberg (2010), uma vez determinadas as estratégias alternativas, o próximo passo é avaliá-las e escolher a melhor. Em outras palavras, supõe-se que várias estratégias alternativas foram projetadas e devem ser avaliadas para que uma seja selecionada. 


\section{Diagnóstico da situação problema e oportunidade}

O atendimento correto é capaz de fazer a diferença entre uma empresa e seus concorrentes, e este é um senso comum entre vários especialistas. Portanto, se uma equipe de atendentes é capaz de cativar um cliente, as chances de fidelização deste mesmo cliente são mais prováveis. Mas mesmo de posse dessas informações ainda somos surpreendidos com um atendimento de má qualidade, demora, despreparo e de um interesse desmedido por vendas a qualquer preço (nesse caso a insistência desmedida). Pior que isso tudo para um cliente é ainda ter que se deparar com atendentes/vendedores que acreditam estar nos fazendo um favor em atender a eles. (BOULDERS, 2015)

Figura 1: Processo de Organização

\section{FASE 1}

Organização das Rotinas da Empresa

Elaboração de estratégias de Rotina

\section{FASE 2}

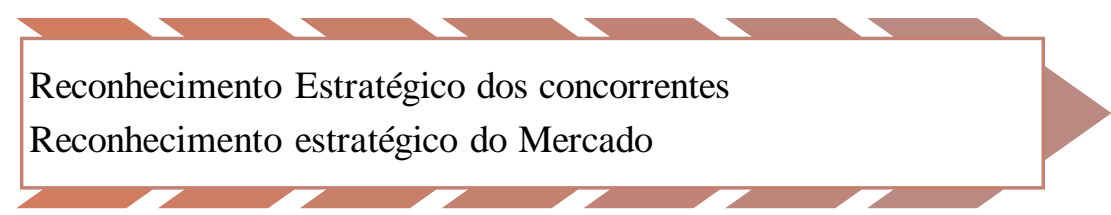

\section{FASE 3}

Estipulação de um diferencial Competitivo

Argumentos próprios e singualares para a realização de vendas

Fonte: Kelley (2019)

$\mathrm{O}$ ato de atender compreende a noção de entender bem o seu cliente e fazer de tudo para satisfazer as suas vontades. Em outra definição temos as considerações que dizem que é preciso que se atente às normas de atendimento diferenciado, neste ramo há que se considerar as diferentes concepções de atendimento e regras de convivência a fim de que seja possível uma melhor compreensão de suas finalidades. (GONÇALVES, 2020)

As definições de bom atendimento são de fundamental importância e facilmente aplicáveis ao contexto empresarial. A utilidade destas regras se dá na 
necessidade de o cliente estar atualizado e não poder ficar à mercê de sua vontade de comer, não se pode querer que o cliente se utilize de seus serviços e pronto. É inadmissível que o cliente simplesmente vá a um estabelecimento e não receba nenhum tipo de reconhecimento referente à sua presença, enfim não se sinta importante de alguma forma. (KELLEY, 2019)

Os cenários empresariais são considerados altamente competitivos e em estão sempre em constantes mudanças. A liderança apresenta a cada dia novas maneiras de pensar e desenvolver estratégias para gerir as empresas. Para Loures e Schelemm (2019), pode-se então afirmar que a liderança tem como principal função o desenvolvimento de pessoas.

De modo geral, é preciso que se diga que, a possibilidade de uma expansão comercial e de considerável aumento de lucratividade, não poderá acontecer, sem que para isso, haja o emprenho no domínio de forças que validam cada um dos pontos que sustentam um modelo de atuação bem articulado e focado no crescimento e no avanço de uma empresa, de forma segura e bem ordenada, tendo como fonte de resultado, o seu crescimento em todos os sentidos. (GOMES, 2013)

No mundo empresarial, a negociação se apresenta com uma forte ferramenta para obter melhores resultados e é uma competência muito valorizada. E importante destacar que os princípios da negociação valem para todas as organizações, independentemente do segmento, tamanho ou lucro. (ARAÚJO, 2020)

\subsection{PLANO DE AÇÕES PARA VIABILIDADE DAS MEDIDAS DE MARKETING}

O processo de planejamento estratégico está em constante construção, em um aperfeiçoamento evolutivo que tem variado ao longo dos tempos em um continuum que vai desde o forte e rígido caráter prescritivo e normativo (como um receituário de como se deve elaborar a estratégia) num extremo, até o maleável caráter descritivo e explicativo (a explicação das maneiras como as organizações elaboram a estratégia, como exemplo a ser aprendido ou seguido) em outro extremo (CHIAVENATO, 2013)

As etapas de um planejamento estratégico são delineadas de acordo com a metodologia abordada para o seu desenvolvimento, contudo há um senso de orientação no que diz respeito à ordem e sucessão de execução das tarefas 
contidas em cada etapa que se estabelecem mediante a necessidade das informações que cada uma oferece. Nesse momento as organizações têm o poder de flexibilizar e adaptar as metodologias em acordo com a necessidade do seu negócio; é um processo criativo, porém requer conhecimento prévio.

De acordo com Oliveira (2018), é necessário ter o conhecimento detalhado e aprofundado de uma metodologia de elaboração e implementação do planejamento estratégico, salientando que é necessário ter o domínio da teoria e da prática, ou ser assessorado por quem detém esses conhecimentos, pois dessa forma o executivo terá embasamento teórico para otimizar sua aplicação.

No estudo, Making Strategy: Learning by Doing, de Christensen (1997), foi relatada a experiência de uma empresa, com estabilidade no mercado, que, em detrimento do avanço da tecnologia, se viu ameaçada pela concorrência. Foi determinado, portanto, o desenvolvimento de um planejamento estratégico, contudo, seus executivos não foram capazes de desenvolver uma estratégia eficiente, e após 1 ano, apesar de extraordinários esforços, pouca coisa havia mudado. Diante do fato, o autor reforça a necessidade do conhecimento teórico e prático para o desenvolvimento de um planejamento estratégico e aponta que é necessário ter uma metodologia estruturada para alcançar o sucesso nos resultados.

Para Bateman e Snell (2012):

O planejamento tático traduz metas e planos estratégicos e gerais em metas e planos específicos aplicáveis a uma determinada parte da empresa, muitas vezes uma área funcional, como marketing ou recursos humanos. Os planos táticos concentram-se nas ações amplas que a unidade precisa realizar para cumprir sua parte do planejamento estratégico. (BATEMAN; SNELL, 2012, p.75)

Neste contexto, fica claro que por ser mais específico e pontual, possui relevada importância para o alcance dos objetivos estratégicos prefixados. Contudo, vale salientar que para desempenhar uma administração tática eficiente, é necessário que se faça a correta utilização dos recursos disponíveis.

Pode-se dizer que planejamento é aquele que faz a "ponte" entre a operação do dia a dia e o futuro da organização. Ele é resultado dos desdobramentos do planejamento estratégico, alinhando os 2 níveis de planejamento supracitados a fim de alcançar os objetivos estratégicos por meio da realização dos planos departamentais. 
Esse planejamento observa as diretrizes do planejamento estratégico e determina objetivos específicos de cada unidade ou departamento, envolvendo assim decisões mais funcionais, focando no médio prazo. Desta forma, o planejamento tático atua traduzindo e interpretando as decisões estratégicas para as ações de gerenciamento que acontecerão na empresa, em planos considerados concretos e direcionados para a execução de suas atividades operacionais. (CAMPOS, 2014)

Por sua vez o planejamento se desdobra em objetivos operacionais onde em que são executadas as ações definidas pelo nível tático para atingir os objetivos das decisões estratégicas.

Todo esse planejamento pode ser determinado como sendo de responsabilidade da gerência mais baixa. Deve ser executado em apoio aos planos estratégicos e intermediários. O planejamento operacional é realizado e controlado por um indivíduo ou pequenos grupos, "basicamente por seus executores, supervisores e líderes, que estão muito próximos da realização da tarefa" (SENAI, 2015, p.12). Todos os envolvidos cuidam do acompanhamento da rotina em ações que são aplicadas em curto prazo, geralmente no período de alguns meses a 1 ano.

Tendo consciência sobre a importância desse modelo de planejamento com o uso e aplicabilidade do CANVAS, se conseguiu determinar para a empresa, as seguintes determinações que seguem apresentadas na ferramenta adiante exposta.

O planejamento estratégico considera toda a empresa em suas ações, contudo, uma abordagem sistemática e integrada dos três níveis de planejamento deve ser considerada, uma vez que na fase do planejamento estratégico as ações são determinadas para o longo prazo, sendo necessários, também, resultados em médio e curto prazos, supridos, portanto, através do desenvolvimento e implantação dos planejamentos táticos e operacionais (OLIVEIRA, 2018).

Para Michael Porter (1986), a essência da formulação da estratégia consiste em lidar com a concorrência. Para Chiavenato (2013), o planejamento estratégico é um processo de formulação e execução de estratégias organizacionais para buscar a competição bem-sucedida da organização e de sua missão e visão no ambiente onde ela atua. Dessa forma o planejamento estratégico pode ser considerado como: 
O planejamento estratégico é o processo contínuo de, com o maior conhecimento possível do futuro considerado, tomar decisões atuais que envolvem riscos futuros aos resultados esperados; organizar as atividades necessárias à execução das decisões e, através de uma reavaliação sistemática, medir os resultados face às expectativas alimentadas. (SILVA; LEON 2015 p. 31)

Desse modo, entende-se o planejamento estratégico como sendo uma ação contínua, um processo que não pode parar, mas que deve estar um passo à frente, a fim de evitar problemas futuros, tendo em vista a busca do sucesso mediante as decisões tomadas (SÁ; GONÇALVES; COELHO, 2020).

Tendo em vista a complexidade do desenvolvimento tanto quanto a necessidade de sucesso do planejamento estratégico, Silva e Leon (2015) atribuíram a responsabilidade de sua elaboração aos dirigentes de mais alto nível da empresa - diretores e assessores, o que não exime a colaboração de um todo empresarial; contudo, os profissionais que possuem uma visão sistêmica e global da empresa quase sempre são os que têm as melhores condições de analisar o negócio internamente, relacionando-o atentamente ao que ocorre no ambiente externo e quais os melhores caminhos/estratégias para a empresa se relacionar com ele.

Em um estudo sobre estratégias organizacionais e planos de negócio, suas interrelações e contribuições para pequenos e micro empreendimentos de sucesso, Oliveira (2018), infere a importância de estratégias tangíveis à realidade do negócio, enfatizando que mesmo não havendo um planejamento bem estruturado, ele jamais pode ser utópico, devendo ser validado sob aspectos reais ao cenário da empresa e suas limitações visando ao atendimento das expectativas, objetivos e metas organizacionais.

As recentes modificações nas relações comerciais que surgiram com o advento da internet estão fazendo com que as empresas de modo geral, se adéquem compassadamente às novas formas de comercialização. Dentre estes fatores, pode-se citar primeiramente, o marketing digital, que surge a partir da utilização das redes sociais como instrumentos fomentadores das relações comerciais. Dentro deste universo surgem as mídias sociais e os profissionais do marketing digital como propulsores para a comercialização de vários produtos e serviços. (CHURCHILL, PETER, 2015)

Ao observar o mercado consumidor atual, depara-se com diversas modificações observadas nas relações comerciais de modo geral, pois se 
entende que são vários os caminhos percorridos pelos consumidores para adquirir produtos e serviços. Dessa forma, é perceptível que o modo como as negociações acontecem no âmbito comercial passam por modificações para se adequar a sociedade que continuamente busca novas formas de viver e se relacionar. Neste passo, é prudente que se estude e compreenda estas dinamicidades sociais no viés comercial como forma de familiarizar-se enquanto profissional - com o novo cenário que se desenha a cada dia. (FAUSTINO, 2019)

No contexto atual, percebe-se que a sociedade de modo geral aderiu com muita propriedade - à utilização de diferentes tecnologias, esta adesão encontra-se diretamente ligada à procura maciça por agilidade e comodismo associados a uma rotina cansativa e em alguns casos enfadonha. Para tanto, a familiarização com o uso de ferramentas que propiciem mais praticidade na vida de todos, como o computador e os celulares, por exemplo, faz com que se encontre mais tempo para organizar-se e desfrutar de algumas comodidades. Provocando nas organizações uma interação que faça uso desses recursos colocados à disposição da sociedade. (KANDYBIN; GROVER, 2019).

Nesse sentido é evidenciada a necessidade de conhecimento e embasamento teórico para um detalhamento metodológico à elaboração e implementação do planejamento estratégico na empresa. Oliveira (2018) ressalta que um planejamento estratégico não deve ser considerado apenas uma afirmação das aspirações de uma empresa, pois inclui, também, o que deve ser feito para transformar essas aspirações em realidade, enfatizando e descrevendo o processo geral do planejamento em três dimensões operacionais: o delineamento, a elaboração e a implementação conforme mostrado na figura 2 adiante exposta:

FIGURA 2 - DIMENSÕES OPERACIONAIS DO PLANEJAMENTO ESTRATÉGICO
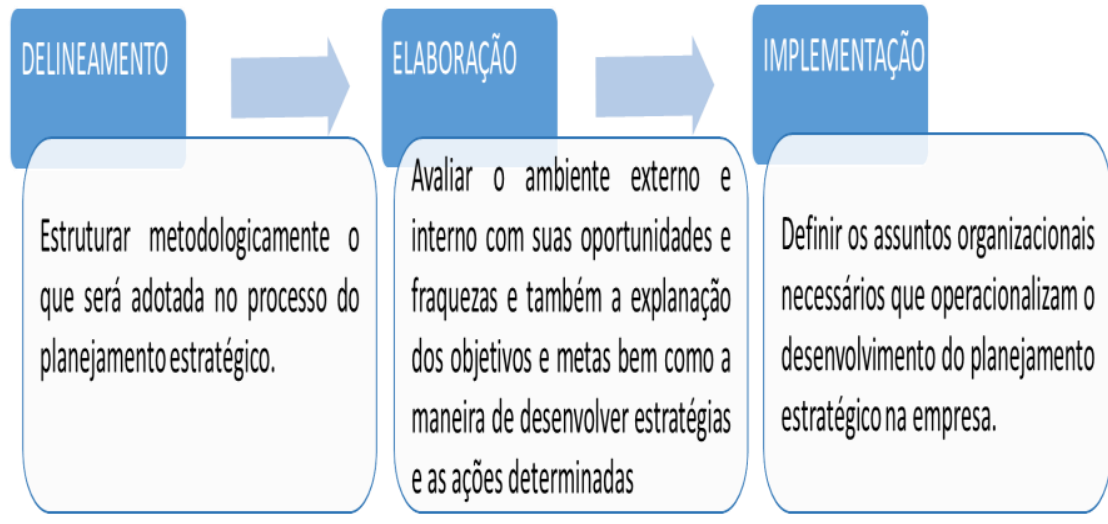

Fonte: adaptado de Oliveira (2018) 
Conforme o entendimento de Moore (2019), o brainstorming se consolida como uma ferramenta que consiste em passos simplórios como a explanação, o entendimento e a consideração de modelos e ideias que podem auxiliar na resolução de um problema específico. Já para Campos (2014), o uso do brainstorming tende a fazer com que um determinado problema dentro de uma organização ocorra de forma mais fluida, uma vez que a maior contribuição dessa ferramenta consiste justamente na valorização dos olhares e na multiplicidade de soluções que podem surgir com a aplicabilidade e usabilidade dessa ferramenta.

O brainstorming, categoricamente tido em sua significância como uma "tempestade de ideias", objetiva o apontamento de uma solução, ou de soluções para um problema encontrado dentro do ambiente organizacional. A ideia na usabilidade e aplicabilidade dessa ferramenta, consiste na sua análise mais aprofundada com foco no modelo institucional apresentado.

De forma direta, Matias (2017) afirma que o brainstorming, quando aplicado em um processo de planejamento estratégico em uma organização, vem aplicado já no início do planejamento, considerando para tanto a multiplicidade de olhares que podem colaborar com a resolução do quadro que se tem apresentado.

A aplicabilidade do Canvas se relaciona com o gerenciamento visual de uma empresa ou de um processo, fazendo com que se possa alcançar melhorias em seu funcionamento e também na viabilização de a execução de um planejamento estratégico.

De acordo com o entendimento de Avelange (2020), o gerenciamento visual tem como meta apontar possibilidades de crescimento, podendo auxiliar na resolução de problemas dentro de uma empresa. Nesse sentido, compreende-se que dentro do cenário da empresa aqui analisada, o uso do Canvas tem como escopo a viabilização de ações mais coerentes com o seu funcionamento, mesmo em um cenário de crise.

Observando assim, vê-se que o Canvas pode ser essencial dentro do campo administrativo da empresa aqui apresentada, observando que, de modo muito simplório, o processo de tomada de decisão precisa ocorrer como base na compreensão de que é indispensável o conhecimento técnico sobre o que está ocorrendo no ambiente organizacional. No entendimento de Gonçalves (2020), sem o auxílio desse tipo de gerenciamento visual o desenvolvimento e crescimento da empresa ocorre, porém de forma incerta. 
A matriz SWOT tem como meta uma análise geral da organização que está sendo sento estudada. Trata-se nesse caso de uma ferramenta que analisa sistematicamente as fraquezas, oportunidades, forças e oportunidades de uma organização, visando com isso à criação de um plano de ação que explore adequadamente cada uma dessas ferramentas, para com isso se ter uma melhoria geral do quadro apresentado.

De acordo com o que se tem exposto em Avelange (2020), a utilização da matriz SWOT, dentro de uma empresa que pretende se organizar de forma sistemática e crescer organizadamente, é de fundamental importância, tendo em vista a possibilidade de melhorias que o reconhecimento das oportunidades e das forças da organização podem contribuir significativamente para 0 desenvolvimento organizacional como um todo.

Desse modo, observa-se também o que se tem demonstrado como suas oportunidades, tendo aí expostos os caminhos que podem ser seguidos rumo a um crescimento mais sólido e coeso da própria organização. A estruturação de uma matriz SWOT, apesar de simples, é profundamente significativa e articulada, e visa com isso à consideração de medidas que podem ser eficientes para o alcance das metas que se quer atingir. (GOMES, 2013) 


\section{Análise da situação e proposta de solução \\ 4.1. PROPOSIÇÕES}

Os processos de aplicação de marketing podem ser relevantes em múltiplos contextos, então pode-se dizer que a consideração de formas de ação dentro de um modelo de negócio pode ser relevante com múltiplas formas de ação e que, quando devidamente aplicadas, podem ser relevantes e responsáveis pelo crescimento de uma organização modelo. (KELLEY, 2019)

Ainda assim, é importante dizer que a usabilidade do marketing visa obter resultados a partir de práticas que se aplicam no plano físico e que possibilitem ações no plano tecnológico essenciais para se pensar em uma forma de ação voltada à compreensão e coesão do marketing. (ALENCAR, 2019)

De acordo com o que se observa em Las Casas (2016), deve-se considerar que a adoção de ferramentas que integram o marketing requer muito mais atenção do que um modelo de ação simplista, que vê o marketing em seu plano geral como uma ferramenta que se resume ao anúncio de uma mercadoria.

Nesse sentido, Araújo (2020) especifica que a condição de um modelo de ação empresarial baseado nos pressupostos do marketing tem a ver com a execução de medidas que possam viabilizar sistematicamente um grande número de medidas que, juntas, são responsáveis por fazer para um negócio.

Além disso, Loures e Schelemm (2019) ensinam que fazer uso do marketing é muito mais criterioso do que se imaginava. Assim, o autor cita a possibilidade de utilizar redes e outras mídias sociais, contratando profissionais que integrem o modo de atuação desse mercado, junto com uma variedade de termos que não podem ser restritos a um único exemplo.

Assim, é pertinente dizer que o trabalho que ora se inicia visa explicitar conteúdos relevantes para a compreensão do marketing, destacando a sua indispensabilidade dentro de um ambiente organizacional, que faz uso preciso de medidas que procuram essencialmente sublinhar a importância de entrar com conhecimento, em um ramo no qual o crescimento de uma organização é imprescindível e se dá a partir de ações de marketing decorrentes do domínio das tecnologias e demais ferramentas que juntas compõem o marketing.

Dentro do processo de Administração, o uso de ferramentas de marketing pode até ser adotado em um primeiro momento, porém, a aplicabilidade de seu uso tende a ser o fator que realmente requer maior observação. 
A observação dos dados relacionados ao uso do marketing mostra que, pela relevância dessas ações neste segmento, otimizam o modus operandi de cerca de $98 \%$ das organizações que utilizam essas técnicas em seu modelo de negócios (PREDEBON, 2020) Dentro do segmento padrão de atividade referente ao marketing, a não análise de métricas e fatores relacionados ao seu uso, torna ainda mais complexa a viabilidade das ações desenvolvidas e, portanto, torna sua utilização ineficaz.

Portanto, Predebon (2020) ensina que é necessário entender que ao se optar por um modelo de ação que possa ser viável para a implementação de ações de marketing, deve-se também ter em mente o fato de que esta não é uma ação vazia e aleatória, é um modelo de ação que exige um olhar muito específico e um conhecimento bem direcionado ao que se deseja.

É evidente que os objetos e serviços vendidos têm períodos de grande e pequena oscilação no mercado, de modo que este é um aspecto que compõe a trajetória de cada bem de consumo.

É importante ressaltar a importância de aproveitar as oportunidades em que determinado produto está em evidência, sendo um momento favorável para se aproximar dos clientes, explorar sua curiosidade e vontade de consumir e finalmente conquistar o melhor posicionamento do produto perante o públicoalvo mercado (LAS CASAS, 2016).

Tendo em vista o posicionamento da marca, destacam-se as características dos produtos por ela oferecidos, tanto ao nível do ciclo de vida em que os produtos se encontram, como da qualidade a eles ligada, sendo fundamental que o produto tenha uma identidade, ou seja, um nome próprio que o faz ser lembrado de forma única.

Segundo Gomes (2013, p. 182) "uma marca é um nome, termo, sinal, símbolo ou desenho, ou uma combinação deles, que pretende identificar os bens e serviços de um vendedor ou grupo de vendedores e diferenciá-los".

Além disso, segundo Gomes (2013, p. 183) "tudo o que se fala sobre o produto é o ideal e, por sua vez, tudo o que foi idealizado é demonstrado por meio dele". Assim, é imprescindível que as organizações garantam a qualidade de seus produtos e serviços, pois o descumprimento das especificações previamente acordadas pode prejudicar a imagem e a credibilidade da empresa.

O preço é o valor monetário aplicado a um produto ou serviço que se pretende comercializar. A partir disso, Churchill e Peter (2015, p. 314) concebem o preço como "a quantidade de dinheiro, bens ou serviços que deve ser dada para adquirir a propriedade ou uso de um produto". 
Portanto, um aspecto fundamental a ser considerado é a adequação do valor percebido pelo cliente ao valor monetário, de forma que deve haver um equilíbrio entre essas duas variáveis. Para os autores supracitados, quando os profissionais de marketing definem o preço de um produto ou serviço, devem ser considerados todos os fatores psicológicos que, de uma forma ou de outra, são importantes para o consumidor.

Assim, a empresa deve utilizar métodos e técnicas capazes de aumentar o valor percebido dos produtos, de forma que os esforços sejam recompensados com o aumento das vendas e a possibilidade de aumento do preço dos produtos em questão.

Afirma-se que na visão apresentada por Etzel e Walker (2016, p. 348) "o papel da distribuição dentro de um Marketing Mix é levar o produto ao seu mercado-alvo. Nesse processo, a atividade mais importante é acertar a venda e a transferência da propriedade, do produtor ao consumidor final ".

Para McCarthy e Perreault (2017, p. 230), a promoção é vista como "a comunicação de informações entre vendedor e potencial comprador ou outros no canal para influenciar atitudes e comportamentos". Ressalta-se que a função básica da promoção é expor aos clientes que o produto por eles desejado está disponível, apresentando um preço adequado às suas vantagens, e que o referido produto está acessível em determinado ponto de venda.

Segundo a visão defendida por Kandybin e Grover (2019, p. 44), “o marketing e a publicidade podem sempre se apresentar e transformar um conceito 'mais ou menos' em sucesso de vendas". Para os mesmos autores, esta afirmação denota a relevância da adoção de medidas coerentes no que diz respeito à aplicação de estratégias promocionais, que é uma ferramenta essencial no posicionamento de uma marca ou produto na esfera do marketing.

\subsubsection{ESTRATÉGIA DE AÇÃO}

O marketing digital é muito mais do que um site, e-mail e mídia social. Também engloba publicação de conteúdo, otimização móvel e análise de dados. É um conjunto de tudo, sendo que cada ingrediente tem uma importância única na mistura.

Marketing digital é uma expressão cada vez mais popular nos dias de hoje; no entanto, a sua popularização aconteceu somente no início do novo milênio, acompanhando a da internet. $O$ acesso à internet criou rapidamente uma nova categoria de marketing, a qual chamamos digital, que é nada mais nada 
menos do que a aplicação dos conceitos de marketing tradicionais aos meios digitais disponíveis hoje em dia (FAUSTINO, 2019).

Nos primórdios do marketing digital, muitos profissionais de marketing de conteúdo simplesmente carregavam conteúdo recheado com palavras-chave que mal podiam ser lidas por usuários humanos. O objetivo desse conteúdo era captar a atenção dos primeiros robôs de mecanismo de pesquisa, programas que rastreiam o conteúdo online para encontrar palavras-chave, links e outros pontos de dados que correspondam à entrada do usuário. Isso rapidamente se tornou uma tendência, e os principais mecanismos de pesquisa como o Google agiram rapidamente para penalizar o uso de palavras-chave e outras táticas (FAUSTINO, 2019).

Atualmente, o Google recompensa os sites pela publicação de conteúdo relevante e de alta qualidade que agrada a um nicho-alvo. Para desenvolver a presença digital é preciso desenvolver uma estratégia de marketing digital sólida que funciona para os objetivos atuais, mas sempre vale investir tempo e esforço para preparar uma estratégia de marketing para o futuro (ANDRADE, 2012).

Conhecer os principais consumidores é fundamental, saber que clientes precisam ser alcançados para alavancar o negócio e quais ainda não se conectaram.

A pesquisa de perfil do cliente pode ser um dos investimentos de marketing mais valiosos. Uma pesquisa de usuário eficaz pode fornecer uma melhor compreensão dos desejos e necessidades do mercado-alvo, ajudar a desenvolver conteúdo que seja mais precisamente direcionado aos interesses e objetivos, e compreender e classificar o cliente para o nicho de forma mais clara (ANDRADE, 2019).

Questionários, pesquisas, testes de usabilidade e testes $A / B$ podem fornecer informações valiosas sobre os clientes-alvo. Desenvolver vários perfis de cliente usando os dados que foram reunidos ao longo do tempo para determinar quem são os melhores clientes, como eles passam o tempo online e as melhores maneiras de alcançá-los com campanhas de marketing eficazes (ANDRADE, 2012).

Quase todas as empresas têm um perfil no Facebook agora, mas outras mídias sociais podem ser fantásticas para se conectar a públicos diferentes. Instagram e Snapchat podem ser locais ideais para exibir novos produtos e fazer o contato de trechos de conteúdo de vídeo. Também são ótimos para conteúdo de fotos, e o Twitter é o lugar certo para obter as notícias mais interessantes e as últimas atualizações. (ANDRADE, 2012) 
Determinar onde os clientes-alvo gastam seu tempo usando a mídia social e tentar cultivar seguidores em uma nova plataforma é necessário para obter engajamento. Passar algum tempo desenvolvendo perfis de clientes e determinar quais plataformas de mídia social são mais atraentes para eles é outro motivo pelo qual a pesquisa completa do usuário é uma ferramenta tão eficaz para a formulação de estratégias (ANDRADE, 2012).

A autoridade da marca aumenta à medida que há conexão mais profunda com o público. Ao fornecer consistentemente ao público conteúdo relevante e provar que sabe do que está falando, se constrói autoridade inerentemente (FAUSTINO, 2019).

A autoridade da marca também tem um impacto significativo no SEO que é o administrador, portanto, é preciso buscar oportunidades de provar a posição como líder do setor. Por exemplo, ao publicar conteúdo no blog e simplesmente listar os autores contribuintes como "equipe" sem criar biografias de autores elaboradas para eles, esta é uma grande oportunidade perdida de construir uma autoridade e ganhar alguns pontos fáceis de SEO (FAUSTINO, 2019).

Embora muitos provavelmente já tenham se adaptado a uma abordagem que prioriza os dispositivos móveis quando se trata de desenvolvimento web e criação de conteúdo, essencial se certificar de levar essas lições para se preparar para o número crescente de pesquisas por voz, procurando maneiras de incorporar mais elementos de PNL SEO, como palavras-chave longtail e strings de palavras-chave mais elaboradas com palavras de preenchimento que os usuários provavelmente falarão nos dispositivos para realizar pesquisas por voz (FAUSTINO, 2019). O conteúdo ainda lidera como a chave para o SEO de sucesso, mas o tipo de conteúdo que se produz pode ser um pouco obsoleto em comparação com o que algumas outras marcas estão oferecendo. O conteúdo de vídeo possui um potencial incrível para praticamente qualquer marca.

Vídeos instrutivos, demonstrações de produtos, visitas às instalações, entrevistas para "conhecer a equipe" e mostras de bastidores são todas possibilidades melhora e aumento de crescimento. O conteúdo de vídeo também é altamente compartilhável, então essa pode ser uma maneira de aumentar a presença nas redes sociais (ANDRADE, 2012). Cada marca é diferente e cada nicho de mercado é diferente, os gostos e comportamentos dos consumidores estão em constante mudança, e pode parecer uma batalha de desgaste para acompanhar as rápidas mudanças das regras de SEO e as demandas do mercado. 
Ao se utilizar da mídia social, todo influenciador procede dessa maneira: Programar postagens para horários e datas específicas, interagir com os comentaristas e responder a mensagens diretas. $\mathrm{E}$ acompanhar $\mathrm{O}$ progresso. Uma ferramenta como a Hootsuite pode ajudar a otimizar todas as suas plataformas e rastrear o engajamento, enquanto o Google Analytics mostra quais páginas estão impulsionando a ação do cliente e quais estão ficando para trás. (SILVANI, 2016).

A globalização encurtou as distâncias e motivou as pessoas a conhecerem novos lugares e viver diferentes culturas e hábitos. Com essa circulação de pessoas pelo mundo, torna-se necessário comunicar as singularidades que o destino possui.

A prática é bem comum nos EUA. Estados e pequenas cidades trabalham o place branding para valorizar atributos e divulgar o espírito do lugar. Um conceito que não abrange apenas a potencialidade, mas a econômica com viés de integração entre lugar e pessoas.

Considerar a finalização de vendas dentro do marketing digital é um processo que requer uma análise detalhada sobre as medidas que são implementadas em todo o processo de ação do marketing realizado. Nesse sentido, compreende-se que sendo uma ação que requer planejamento e detalhamento quanto aos passos a serem executados e que se quer seguir, é importante levar em conta que todas as ações que serão envoltas nesse processo precisam ser planejadas e direcionadas a um foco final, que no caso em questão é a concretização da venda. (FROTA, 2016).

Dentro do marketing digital, é necessário que seja feito o rastreamento do fluxo de visitas e, com isso, se integre de forma coerente o que precisa de fato ser validado e o que precisa ser excluído em decorrência de sua ausência de êxito. Assim, o uso de ferramentas de gerenciamento como o Return on Advertising Spend - ROAS, que em português representa o retorno sobre gastos com anúncios, pode ser uma oportunidade de se analisar o que é ou não exitoso em uma ação de marketing digital (BERTAGLIA, 2016).

Junto a isso, é importante salientar que a consideração sobre as diferentes etapas do funil de vendas pode ser o fator diferencial entre uma ação exitosa e uma ação falha, tendo em vista o fato de que, sem o conhecimento exato sobre a forma como se deve agir, o que se tem é uma constante repetição de atos que são lançados a ermo, na tentativa de converter um público à aquisição de um produto, que nem se sabe ser esse o foco de compra. (BERTAGLIA, 2016) 
Observando todas as fases do funil de vendas, e considerando todas elas, se compreende que a orientação de abordagem sobre essas fases tende a se relacionar como uma condição de análise eficiente e coesa quanto ao cenário apresentado, podendo dessa forma, fazer com que as taxas de conversão aumentem.

Conforme o que se tem em Cunha (2017), os tópicos que integram o funil de vendas estão mais similares a um manual de orientação que estipula passos que podem ser seguidos para a consolidação de uma ação eficiente referente ao marketing digital. Para tanto, é crucial que se compreenda que, a despeito do engajamento gerado, das visitas, dos cliques e das demais ações, todos de grande relevância para o contexto idealizado, é a conversão de todas essas ações em vendas que vai de fato proporcionar o êxito das ações de marketing digital que foram implementadas.

É necessário levar em conta o fato de que, no que se refere às medidas estratégicas que serão tomadas, há que se considerar o fato de que todo 0 contexto em que as empresas atuam nos dias atuais muda de forma ininterrupta (ARAÚJO, 2020).

Junto a isso, a possibilidade de utilização de ferramentas que visem ao alcance de um maior número de pessoas, pede de longe que haja antes de qualquer contato, mesmo o de demonstração descomprometida do serviço ou produto oferecido, o aceite de quem irá ver determinada propaganda. (PONTES, 2018).

Nesse sentido, ao se utilizar por exemplo um disparador de e-mails, ou o auxílio de uma ferramenta como algumas das muitas que estão presentes em lojas virtuais como a do Google, se consegue observar que há a necessidade de realização de uma estratégia especifica sobre o que será ofertado. (KOTLER, 2020).

Dessa forma, é importante estar sempre atento ao modelo de negócio que se quer validar, tendo acima de tudo o entendimento de que as ferramentas que podem ser utilizadas como suporte de comando estratégico e de fomento à competitividade, requerem uma mutação constante e acima de tudo, exigem de quem está a gerir tal processo, o comprometimento e o entendimento sobre o fato de que é preciso bom conhecimento de mercado e acima de tudo, um excelente conhecimento de causa sobre o que se está representando. (QUEIROZ, 2020).

É preciso, nesse caso, que se retorne a um período não tão distante em que o modelo de competitividade era mais simplório, e se referia a medidas 
simples como por exemplo, a possibilidade de redução de preço de uma determinada mercadoria. Assim, o famoso "eu tenho o menor preço" era a grande cartada negocial, fazendo compreender que a condição de competitividade se restringia unicamente a este fator.

No que se refere à questão estratégica por exemplo, pode se apontar como exemplo, o modelo batido de anúncios realizados em veículos de comunicação, com as possibilidades de fazer com que o maior alcance de pessoas, já era em alguns casos, fator suficiente para fazer com que já se conseguisse uma maior quantidade de consumidores (ROBBINS, 2020).

A compreensão sobre a inovação disruptiva se relaciona com a possibilidade de transformação de um produto ou de oferta de um serviço. Tratase de um modelo de ação bem direcionado ao entendimento de que a condição de mutação em um negócio está sempre presente. Nesse sentido, toma-se como base para a compreensão sobre as mudanças que podem ocorrer em um modelo de negócio, os processos evolutivos, com a adoção de ferramentas que de longe se destacam como essenciais para a condição de melhoramento de serviços.

Nesse sentido, há que se destacar que o processo de evolução de que se fala tem relação direta com certa superioridade que precisa ser notada pelos consumidores, encaixados aí questões como a simplicidade e facilidade de acesso, bem como a conveniência de seu uso.

Por esse motivo, se compreende que ao falar sobre esse processo de mudança que foi trazida a empresas diversas em decorrência das constantes possibilidades de inovação que surgem no mercado, se tem, de modo implícito em tal tema, a constante usabilidade de tecnologias que podem sim ser pertinentes com a melhoria na oferta de serviços e produtos de uma organização.

Obviamente todos esses processos tornam as soluções apresentadas em momentos anteriores obsoletas, e, nesse sentido, se constata que a necessidade de se estar ciente de todas essas mudanças é essencial para quem deseja se manter aproveitando tais processos de inovação nas negociações.

Conceitualmente, pode-se analisar que a teoria da inovação disruptiva foi verificada inicialmente no ano de 1995 com Joseph L. Bower, que determinava que a disrupção em um negócio de fato ocorria quando uma organização com quantidade de recursos inferiores era capaz de desafiar a estabilidade de empresas já conhecidas e consolidadas em seu ramo de atuação. 
Nesse sentido, se tem como base de análise o caso da ferramenta de controle do Google Analytics que tende a ser uma ferramenta modelo que consolida de forma a analisar o tráfego e interação de clientes que navegam por determinado site. A partir desse tipo de medida, se considera que a utilização do Google Analytics permite ao administrador a possibilidade de gerir de forma mais segura o seu negócio, visualizando e compreendendo os pontos em que a sua empresa possui um bom potencial de interação, e os pontos em que é preciso trabalhar para melhorar.

Dentro do contexto de administração dos tempos contemporâneos, há que se observar que os conceitos de estratégia e de competitividade têm mudado de forma considerável. Nessa concepção e entendimento sobre mudança, se leva em conta o fato de que, nos modelos de negócio que se organizam na atualidade, em que há a possibilidade de uso de uma gama de ferramentas que tendem a auxiliar de modo significativo no processo de desenvolvimento de uma empresa, há que se levar em conta as ferramentas de marketing voltadas para o uso estratégico, no que se refere à competição com a concorrência, e que fazem com que se possa ganhar destaque dentro do contexto corporativo. (KELLEY, 2019)

Nesse ponto, cabe dizer que a gestão de estratégia e competitividade é uma ciência, um modelo de gestão que, como todo processo de gerenciamento, é passível de equívocos, caso o comprometimento profissional ocorra de forma superficial ou leviana. A gestão, nesse sentido, deixa implícita a necessidade de entendimento teórico sobre o tema em questão, abarcando toda a multiplicidade que esse tema possui. (LOURES; SCHELEMM, 2019)

Junto a isso, é indispensável também a compreensão quanto ao fato de que essa gestão ocorre fundamentada na familiaridade e domínio de técnicas que vão além dos macetes que habitam o senso comum. Logo, as máximas que indicam a necessidade de agir de acordo com A ou B, estar sempre procurando buscar engajamento em redes sociais e ter o preço mais baixo do mercado, representam tão somente apontamentos vagos que não consideram a singularidade de cada indivíduo e que estão distantes de um modelo de gestão que realmente valide as particularidades de cada empresa ou pessoa (PONTES, 2018).

Para tanto, se observa um crescente uso de ferramentas que se conectam com a possibilidade de observação sobre táticas e estratégias que são importantes para o crescimento de uma empresa, consegue-se também observar que, de acordo com dados do próprio Google, uma grande quantidade 
de empresas faz uso do Google Analytics como forma de entender melhor o seu poder de alcance dentro do seu campo de atuação.

Em síntese, pode-se dizer que o uso do Google Analytics pode, sim, ser considerado como uma ferramenta que auxilia consideravelmente na definição de estratégias e competitividade para uma organização, ao passo que também age disruptivamente no sentido de inovar tecnologicamente quanto à sua forma de ação.

Desta feita, é saudável reiterar que a consideração quanto à eficácia da gestão estratégica e de competitividade leva em conta o conhecimento histórico e entendimento macro sobre a atual condição de quem busca por essa gestão. Assim, é importante dizer que o diagnóstico e prognóstico sobre esse tipo de situação precisa ocorrer de forma singularizada, dando ênfase, nessa análise, ao perfil de cada um. (LAS CASAS, 2016)

Com isso, chega-se ao entendimento de que um dos princípios de uma gestão realmente coesa habita na validação de unicidade dos casos que se tem à frente. 


\section{CONSIDERAÇÕES FINAIS}

Os processos de aplicação são pertinentes dentro de múltiplos contextos. Desse modo, a consideração de formas de ação dentro de um modelo de negócio pode ser pertinente com múltiplas formas de ação e que, quando bem aplicadas, podem ser relevantes e responsáveis com o modelo de crescimento de uma organização.

Mesmo assim, é importante dizer que a usabilidade do marketing digital tem resultados a partir de práticas que são aplicadas no plano físico e que viabilizam ações no plano tecnológico que são essenciais para a consideração de uma forma de ação voltada ao entendimento e coesão do marketing enquanto ferramenta essencial dentro de uma organização.

Há que se considerar que a adoção das ferramentas que integram o marketing digital necessita de mais atenção que um modelo de ação simplória, que vê o marketing em seu plano geral como uma ferramenta que se resume ao mero anúncio de uma mercadoria.

A condição de um modelo de ação empresarial com base nos pressupostos do marketing digital com relação com a execução de medidas que podem, sistematicamente, viabilizar uma grande quantidade de medidas que juntas, são responsáveis por fazer com que um negócio cresça de forma ordenada.

Dessa forma, é pertinente dizer que o trabalho tem como meta a explanação de conteúdos relevantes para a compreensão do marketing digital, enfatizando a sua indispensabilidade dentro de um ambiente organizacional, que faz uso preciso de medidas que essencialmente procuram ressaltar a importância de se adentrar com conhecimento, em um ramo em que o crescimento de uma organização é indispensável e acontece com base em ações mercadológicas advindas do domínio de tecnologias e de demais ferramentas que, juntos, integram o marketing digital.

A estratégia evolui e muda com o tempo, à medida que os executivos da alta administração tomam decisões significativas para seu futuro, lançando novas ideias sobre o horizonte estratégico da empresa.

A estratégia resulta de dois tipos diferentes de atividade inteligente, sendo que algumas decisões estratégicas são motivadas por problemas impostos aos executivos, enquanto outras resultam da busca ativa em direção a 
novas oportunidades. No primeiro caso, ocorrem estratégias de solução de problemas e, no segundo, estratégias de procura de novas alternativas.

As decisões estratégicas não são programadas e, muito menos, previstas com antecipação. Elas são tomadas quando as oportunidades e os problemas ocorrem. Nesse sentido, as decisões estratégicas são contingenciais e baseadas em juízo de valor.

Como não é possível prever, com clareza, quando os problemas e as oportunidades surgirão, torna-se extremamente difícil integrar diferentes decisões estratégicas em uma única estratégia explícita e compreensiva. 


\section{Referências}

ALENCAR, Eunice S. A gestão da criatividade. São Paulo: Makron Books, 2019.

ANDRADE, Z. Vida para Consumo a transformação das pessoas em mercadoria. Rio de Janeiro: Jorge Zahar Editora. 2019

ANSOFF, Heidy Vincet. Virtual Business. Disponível em: <http://www.scholtobusiness.com > 1990

ARAÚJO, Tarsis Camilo de Araújo. O consciente. Monografia, Centro Universitário de Belo Horizonte. 2020

AVELANGE, José Ernesto Lima. As empresas são grandes coleções de processos. RAE - Revista de Administração de Empresas, v. 40, n. 1, jan./mar. p. 6 a19. 2020.

BATEMAN, S.; SNELL, A (2012). Da produção ao consumo: impactos socioambientais no espaço urbano. São Paulo: Cultura Acadêmica.

BERTAGLIA, Mark H. Texto: Criando valor público por meio de parcerias público-privadas. Revista do Serviço Público. Brasília 58 (2): 151-179 Abr/Jun 2016.

BOULDERS, Adam. News Business in the New society. Magazine Routers 2015.

BROCKA, Bruce. Gerenciamento da qualidade; tradução e revisão técnica Valdênio Ortiz de Sousa. São Paulo. Makron Books, 2019.

CAMILO, Ronald Darwich. Modelagem dinâmica da gestão: passos para a excelência e resultados superiores. Belo Horizonte. Instituto Qualidade Minas, 2013.

CAMPOS, Vicente Falconi, TQC: gerenciamento da rotina do trabalho do diaa-dia. Belo Horizonte: UFMG e Fundação Cristiano Ottoni. 3ed. Rio de Janeiro. Bloch, 2014.

CHIAVENATO, Idalberto. Introdução à teoria geral da administração. 4ed. São Paulo. Makron Books, 2013.

CHRISTENSEN, Stephen P. Comportamento organizacional. 11a․ ed. São Paulo: Pearson Prentice Hall, 1997.

CHURCHILL, G. A. J.; PETER, J. P (2015). Marketing: criando valor para os clientes. 2 ed. São Paulo: Saraiva.

CUNHA, G. Saber marketing. Barueri: Manole. 2017

DE SORDI, José Osvaldo. Gestão por processos: uma abordagem da moderna administração. 2ed. São Paulo. Saraiva, 2020. 
ETZEL, M. J.; WALKER, B. J (2016). Marketing. 11 ed. São Paulo: Makron Books. 2016

FAUSTINO, Paulo (2019). Marketing Digital na Prática: Como criar do zero uma estratégia de marketing digital para promover negócios ou produtos. Editora: DVS EDITORA; $1^{\text {a }}$ edição 22 maio.

FERNANDES, Alexandre \& BERTHON, Marilia (2005). Segmentação: panorama atual. In PANOSSO NETTO, Alexandre \& ANSARAH, Marilia (Editores). Segmentação do mercado turístico: estudos, produtos e perspectivas. São Paulo: Manole.

FROTA, A. L (2016). Plano de Marketing para Micro e Pequenas Empresas. $4^{a}$ ed. São Paulo: Atlas.

GOHR, Mirian; SANTOS, Karina Toledo (2017). Um cenário de mudanças. In REJOWSKI, Mirian (Org.). Turismo no percurso do tempo. São Paulo: Aleph.

GOMES, E. Marketing de relacionamento total: gestão de marketing, estratégias de relacionamento e abordagem de CRM para economias de rede; Trad. Marina Barbieri Campomar e Jonathan Hogan - 2.ed. - Porto Alegre: Boolman. 2013

GONÇALVES, José Ernesto Lima. Processo, que processo? RAE - Revista de Administração de Empresas, v. 40, n. 4, out./dez. p. 8 a 19.2020.

KANDYBIN, S.; GROVER, A (2019). Da produção ao consumo: impactos socioambientais no espaço urbano. São Paulo: Cultura Acadêmica.

KELLEY, Robert Earl. Como brilhar no trabalho: nove estratégias decisivas para o sucesso. Rio de Janeiro: Campus, 2019.

KOTLER, P.; ARMSTRONG, K. L. Administração de marketing. 12 ed. São Paulo: Pearson Prentice hall.

KOTLER, Philip. Armstrong, Gary. Princípios de Marketing. Rio de Janeiro. Editora PHP, 2020.

LAS CASAS, A. L. Plano de Marketing para Micro e Pequena Empresa. 4 ed. São Paulo: Atlas. 2016

LOURES, Rodrigo Costa da Rocha; SCHELEMM, Marcos. Gestão financeira em ambientes organizacionais: teorias, reflexões e práticas. Curitiba: Ibpex, 2019.

MATIAS, Maria Sonalba Linhares Leitão. Dissertação: Uma análise crítica das competências da ANATEL para execução da sua missão institucional. Brasília. Fundação Getulio Vargas, 2017

McCARTHY, F.; PERREAULT, R. O consumo e o crédito na sociedade contemporânea. Gestão e Desenvolvimento, 19, 91-114. 2017

MINTZBERG, Eunice Laçava. Novas Teorias e Profissionais da Administração. 5. ed. São Paulo: Atlas, 2010. 
MOORE, Mark H. Criando Valor Público: Gestão Estratégica no Governo. Rio de Janeiro: Uniletras; Brasília: ENAP, 2019.

MOREIRA, Margarida Maria Krohling. Relações Públicas e Modernidade: novos paradigmas na comunicação organizacional. 3. ed. São Paulo: Summus, 2015.

OLIVEIRA, Cássio (2018). O tamanho do mercado do marketing de influência no mundo em 2020. Disponível em: www.influency.me/blog/tamanho-domercado-do marketing-de-influência-no-mundo-em-2020.

PONTES: Maria Aparecida F. de. Novas tendências mercadológicas. São Paulo: Excellus e Consultoria, 2018

PORTER, M. Criatividade hoje: como praticar, aprender e ensinar. São Paulo: Atlas, 1986.

PREDEBON: Maria Aparecida F. de. Novas tendências mercadológicas. São Paulo: Excellus e Consultoria, 2020

QUEIROZ, Marcelo. Organização x pessoas: uma relação de dependência cultural. Administradores.com, out.2020.

ROBBINS, Paulo Daniel Barreto. Excelência em gestão pública: a trajetória e a estratégia do gespública. Rio de Janeiro. Qualitymark, 2020.

SILVA, Mauriti e LEON, Maria Elisa Bastos. O processo nosso de cada dia: modelagem de processos de trabalho. Rio de Janeiro: Qualitymark Editora, 2015

SILVANI Mário Sérgio. O tombamento da gestão empresarial por meio da gestão por processos. Paper - Gauss Consulting Group. www.gausconsulting.com.br, 2016.

TAVARES: Nanscir Faces da Cultura e da Comunicação Organizacional/ Marlene Marchiori, organizadora. - 2 ed. - São Caetano do Sul, SP: Difusão Editora, 2013.

UGAYA, G. Conhecendo o marketing. Barueri: Manole. 2019

VARGAS, Andrew J. Fundamentos do Comportamento Organizacional. Editora Cengage, Ano 2015. 